Research Article

Malays. j. med. biol. res.

\title{
Occupational Exposure to Ionizing Radiation in Interventional Cardiology Practices in Bangladesh during 2010-2014
}

\author{
Mohammad Sohelur Rahman ${ }^{1 *}$, Aleya Begum², Md. Rezaul Karim Khan ${ }^{3}$, Md. Ashraful Hoque ${ }^{4}$, M.M. \\ Mahfuz Siraz \\ ${ }^{1}$ Principal Scientific Officer, Health Physics Division, Atomic Energy Centre, 4 Kazi Nazrul Islam Avenue, Shahbag, Dhaka-1000, BANGLADESH \\ ${ }^{2}$ Chief Scientific Officer and Head, Health Physics Division, Atomic Energy Centre, 4 Kazi Nazrul Islam Avenue, Shahbag, Dhaka-1000, BANGLADESH \\ ${ }^{3}$ Senior Scientific Officer, Health Physics Division, Atomic Energy Centre, 4 Kazi Nazrul Islam Avenue, Shahbag, Dhaka-1000, BANGLADESH \\ ${ }^{4}$ Chief Engineer, Health Physics Division, Atomic Energy Centre, 4 Kazi Nazrul Islam Avenue, Shahbag, Dhaka-1000, BANGLADESH \\ ${ }^{5}$ Scientific Officer, Health Physics Division, Atomic Energy Centre, 4 Kazi Nazrul Islam Avenue, Shahbag, Dhaka-1000, BANGLADESH
}

*Correspondence (Email): msrahman74@hotmail.com

\begin{abstract}
Objective: The objective of this study is to assess, analyze and discuss the occupational exposure to ionizing radiation in interventional cardiology practices in Bangladesh for the last 5-year periods.

Method: Each year, about 100 workers working in interventional cardiology departments of big hospitals in Dhaka City were monitored using Harshaw Thermoluminescent Dosimeters (TLDs) for quarterly basis. The effective dose of the occupational workers were measured using Two Harshaw TLD Readers (one is manual TLD reader, model-4500, and another is automatic TLD reader, model 6600 plus).

Finding: The average annual effective dose (about $80 \%$ workers) in interventional cardiology practices were $<2 \mathrm{mSv}$ in 2010-2014 and no monitored workers were found to have received an occupational exposure $>50$ $\mathrm{mSv}$ in a single year or $>100 \mathrm{mSv}$ in a 5 year period. The status and trends in occupational exposure demonstrate that radiation protection conditions at the majority of the workplace were adequate. Despite that, further optimization is necessary due to large variations observed in the maximum individual doses over the 5-year periods.
\end{abstract}

Key words: Interventional Cardiology, Ionizing Radiation, Occupational Health, TLD, Dose limit

\begin{tabular}{ll}
\hline 12/31/2016 Source of Support: Nil, No Conflict of Interest: Declared \\
\hline $\begin{array}{l}\text { This article is is licensed under a Creative Commons Attribution-NonCommercial } 4.0 \text { International License. } \\
\text { Attribution-NonCommercial (CC BY-NC) license lets others remix, tweak, and build upon work non-commercially, and although the new works must also } \\
\text { acknowledge \& be non-commercial. }\end{array}$
\end{tabular}

\section{INTRODUCTION}

Interventional cardiology is a branch of cardiology that deals with diagnosis and treatment of heart diseases using image-guided catheters. Most imaging equipment used for this purpose is X-ray fluoroscopy with a possibility of changing projections without patient moving (c-arm) and production of high-quality image series (cine mode). Occupational radiation doses in fluoroscopy-guided interventional procedures are highest among medical staff using X-rays, particularly cardiologists involved in interventional procedures (Vano et al., 1998), (Beganovic et al., 2010), (Basic B et al., 2010). The danger of radiation, such as radiation-induced cataracts in occupational workers (Vano E et al., 1998), (Ciraj-Bjelac O et al., 2010), (Jacob S et al., 2010), has led to a significant focus on radiation safety in the cardiac catheterization laboratory.

Any individual radiation monitoring program has at least two common aims. The first aim is to provide information on the adequacy of protection measures which is a input for operational decisions related to the optimization principle (ICRP, 2007), (IAEA GSR part-3, 2014). Secondly, the individual monitoring programs aim to demonstrate compliance with the relevant dose limits as required by the international recommendations and standards (ICRP, 
2007), (IAEA GSR part-3, 2014). In this context, the annual effective dose to the occupationally exposed workers should not exceed $20 \mathrm{mSv}$ averaged over a defined period of 5-year, with a provision that the individual dose does not exceed $50 \mathrm{mSv}$ in any single year. Regular assessment of occupational radiation exposures and the analysis of related trends are vital to examine changes that have taken place over time due to regulatory operations or technological improvements. The objectives of this paper were to present the occupational radiation exposure in interventional cardiology practices in Bangladesh and to evaluate the related trends over a period of 2010-2014.

\section{Materials AND MethodS}

Monitoring of occupational workers by the Health Physics Division (HPD), Atomic Energy Centre, Dhaka (AECD) using Thermoluminescent Dosimeters (TLDs) begin immediately after a facility is licensed to operate. HPD, AECD is the only institute that provides dosimetry service for facilities that employ the use of ionizing radiation in Bangladesh. LiF:Mg,Ti (TLD-100) dosimeters have been in use throughout the period 2010-2014. In the same period, two Thermoluminescent Dosimetry systems have been employed to read Thermoluminescent Dosimeters (TLDs). They are Harshaw Manual TLD Reader, Model 4500 (from 2000 and still running) and Automatic TLD Reader, Model 6600 Plus (from June 2014) with a manual system of data transfer. Harshaw 6600 plus Automatic TLD Reader (Harshaw TLD Reader, Model 6600 plus manual, 2007), which is one of the most technically advanced dosimetry systems for whole body, extremity, neutron and environmental monitoring, is being used by the HPD, AECD. The system offers 'one dosimetry solution' by its ability to monitor whole body (beta, photon, and neutron), extremity and environmental exposure with a single dosimeter. It can take up to 200 dosimeters per cycle and also saves significant time by virtue of its automatic calibration capabilities. It has a flat panel display and touch-screen operation service, and it exceeds International Electrotechnical Commission (IEC), International Organization for Standardization (ISO) and American National Standards Institute Performance requirements. The Harshaw TLD Readers were connected to an external personal computer (PC) and are operated through installed menu-driven WinREMS software.

The Secondary Standard Dosimetry Laboratory (SSDL) has been available at Bangladesh Atomic Energy Commission (BAEC) since 1991, which is traceable to the Primary Standard Dosimetry Laboratory (PSDL) of National Physical Laboratory (NPL), UK. The performance of BAEC SSDL is maintained according to the requirements of the International Atomic Energy Agency (IAEA)/World Health Organization (WHO) network of SSDLs. Therefore, the evaluated doses are traceable to the international measurement system. As an input to support this traceability, the personal monitoring laboratory regularly participates in inter-laboratory dose comparisons as organized by IAEA. In the latest comparison, adequate performance was achieved according to the standards trumpet curve criteria (IAEA, RS-G-1.3, 1999), (ICRP 27 -1, 1997). For all individual doses, the background radiation dose is subtracted, and the minimum detectable level (MDL) is $0.05 \mathrm{mSv}$ for three months for two TLD systems were taken as dose recording level. Those Occupational workers who received doses less than MDL was regarded as zero (0). Table I shows the number of monitored workers for the years 2010-2014.

Table I: Number of monitored workers in interventional cardiology practices for the years 2010-2014.

\begin{tabular}{|l|c|c|c|c|c|}
\hline Type of worker/Year & 2010 & 2011 & 2012 & 2013 & 2014 \\
\hline Physician & 46 & 45 & 46 & 42 & 46 \\
\hline Non-physician & 58 & 50 & 49 & 49 & 56 \\
\hline Total & $\mathbf{1 0 4}$ & $\mathbf{9 5}$ & $\mathbf{9 5}$ & $\mathbf{9 1}$ & $\mathbf{1 0 2}$ \\
\hline
\end{tabular}

\section{Data Analysis}

In this study, four quantities as recommended elsewhere (UNSCEAR 2000) were used to analyze individual doses for the years 2010-2014. They include the annual collective effective dose, the average annual effective dose, the individual dose distribution ratio and the annual collective effective dose distribution ratio. In addition, the minimum and the maximum values of the annual individual effective doses were analyzed to complement the average annual effective doses.

Annual collective effective dose (S)

The annual collective effective dose (S) was obtained according to the following equation (UNSCEAR 2000):

$$
S=\sum_{i=1}^{N} E_{i}
$$

Where $E_{i}$ is the annual effective dose received by the $\mathrm{i}^{\text {th }}$ worker and $\mathrm{N}$ is the total number of workers monitored. The parameter $S$ gives an estimate of the impact of particular practice on the population in given time frame. 
Average annual effective dose

The average annual effective dose $E$ was obtained from the ratio $\mathrm{S} / \mathrm{N}$, where the meaning of symbols are the same as in equation (1).

The individual dose distribution ratio

The individual dose distribution ratio, NRE was obtained according to the following equation (UNSCEAR 2000):

$$
N R_{E}=\frac{N(>E)}{N}
$$

Where $\mathrm{N}(>\mathrm{E})$ is the number of workers receiving annual dose exceeding $\mathrm{E} \mathrm{mSv}$. In this study, $\mathrm{NR} E$ was analyzed for values of $\mathrm{E}$ of $15,10,5$ and $1 \mathrm{mSv}$. The parameter $\mathrm{NR}_{\mathrm{E}}$ provides an indication of the fraction of workers exposed to higher levels of individual doses.

The annual collective dose distribution ratio

The annual collective dose distribution ratio, SRE was obtained according to the following equation (UNSCEAR 2000):

$$
S R_{E}=\frac{S(>E)}{S}
$$

Where $S(>E)$ is the annual collective dose delivered at an annual dose exceeding $E$ mSv. In this study, SRE was analyzed for values of $\mathrm{E}$ of 15, 10, 5 and $1 \mathrm{mSv}$. The parameter SRE provides an indication of the fraction of the collective dose received by workers exposed to higher levels of individual doses.

\section{RESULTS AND Discussion}

\section{Annual collective dose and average effective dose}

Annual collective effective dose and average annual effective dose per exposed worker values are calculated separately for each of the year 2010-2014 periods, and the data have been presented in Fig. 1 and Fig. 2 respectively. The maximum annual collective effective dose of 208 person.mSv for the 5-year study period was recorded in 2012 and the minimum of 108 person.mSv was recorded in 2010. It can be seen that there were no visible dose trends for interventional cardiology practices for the year 2010-2014 periods. The average annual effective dose of occupational workers in interventional cardiology practices are 1.04, 1.40, 2.18, 1.66 and $1.30 \mathrm{mSv}$ for the year 2010, 2011, 2012,2013 and 2014 respectively. Trends in the average annual effective doses were largely similar to the trends in the annual collective effective doses. From the data collected for the year 2010-2014, no occupational workers were found to have received an effective dose $>50 \mathrm{mSv}$ in a single year or $>100 \mathrm{mSv}$ in a consecutive 5-year period. Therefore, occupational exposure to ionizing radiation of all workers in interventional cardiology practices is lower than the prescribed dose limit by ICRP 2007 and IAEA GSR part-3, 2014. However, very few workers (2\% in 2011, 1\% in 2012 and 2\% in 2013) individual effective doses are higher than average annual dose limit (20 mSv. $\left.\mathrm{y}^{-1}\right)$ (ICRP, 2007), (IAEA GSR part-3, July 2014). Therefore, occupational workers in interventional cardiology practices should pay more attention to radiation protection procedures and guidelines to keep the doses below the annual average dose limit other than the maximum allowable dose limit in a year. The status and trends in occupational exposure demonstrate that radiation protection conditions at the majority of the workplace were adequate. Despite that, further optimization is necessary due to large variations observed in the maximum individual doses over the 5-year periods (Table II).

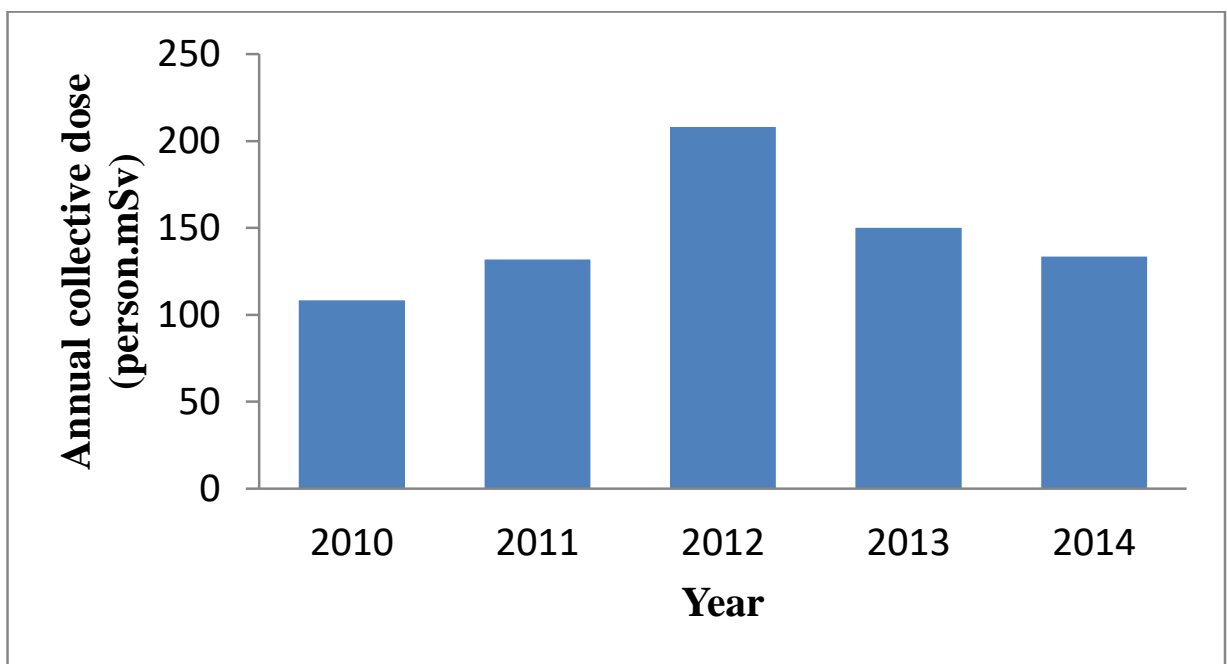

Fig. 1 Annual collective dose of occupational workers for 2010-2014 periods 


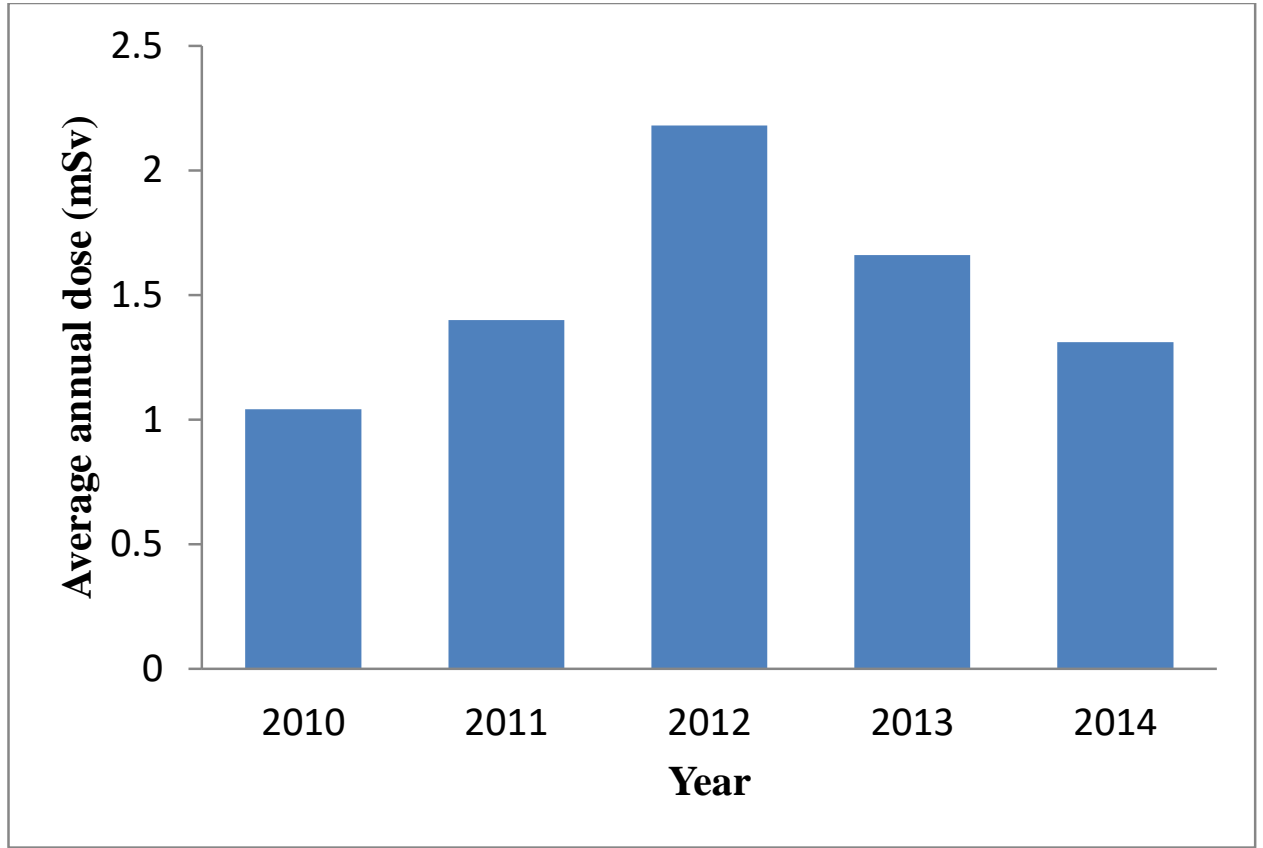

Fig. 2 Average annual dose of occupational workers for 2010-2014 periods

Table II: The maximum (max) and minimum ( $\mathrm{min}$ ) annual individual doses in mSv for the years 2010-2014.

\begin{tabular}{|l|c|c|c|c|c|c|c|c|c|c|c|}
\hline Type of worker/year & \multicolumn{2}{|c|}{2010} & \multicolumn{2}{c|}{2011} & \multicolumn{2}{c|}{2012} & \multicolumn{2}{c|}{2013} & \multicolumn{2}{c|}{2014} \\
\hline & $\max$ & $\min$ & $\max$ & $\min$ & $\max$ & $\min$ & $\max$ & $\min$ & $\max$ & $\min$ \\
\hline Physician & 10.66 & 0 & 26.24 & 0 & 18.14 & 0 & 22.68 & 0 & 15.00 & 0 \\
\hline Non-physician & 10.32 & 0 & 23.72 & 0 & 40.82 & 0 & 49.37 & 0 & 6.00 & 0 \\
\hline
\end{tabular}

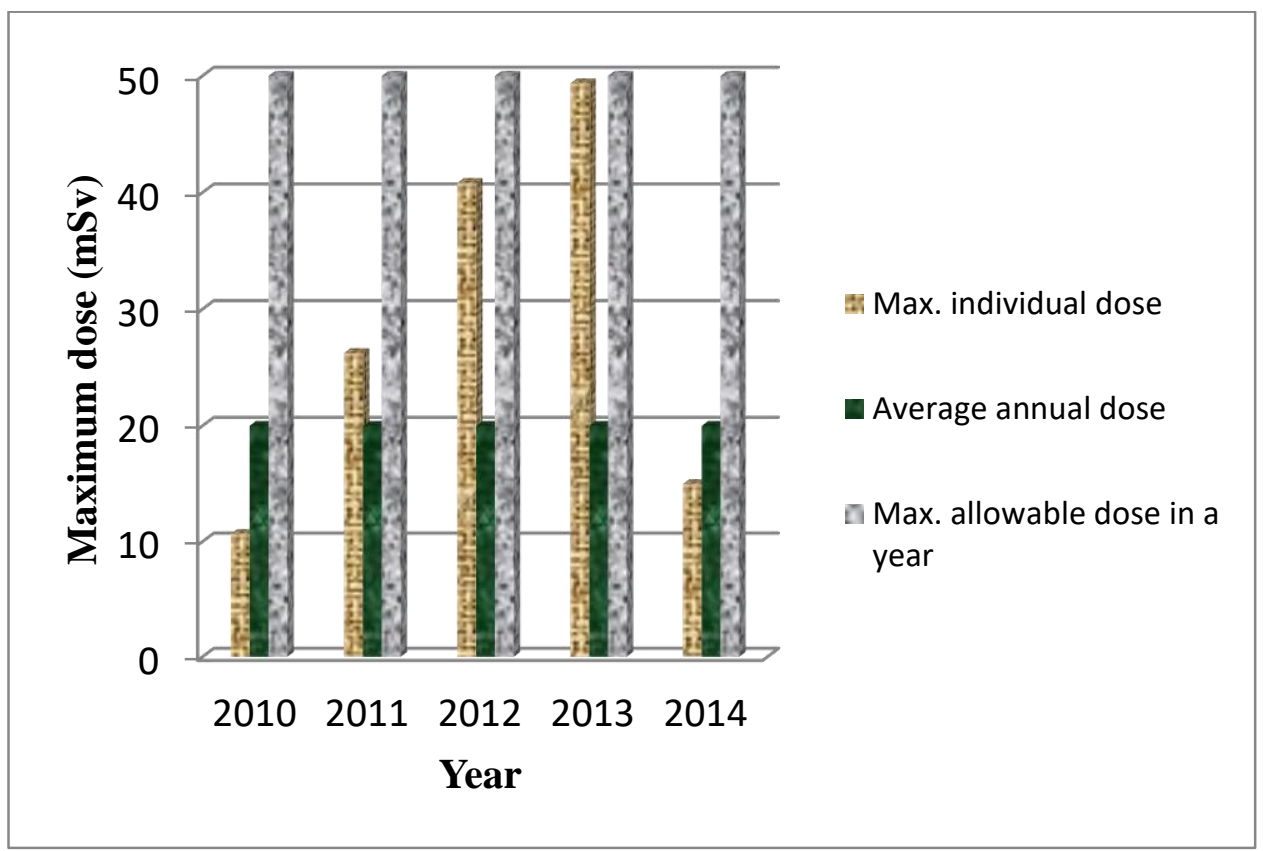

Fig. 3 The maximum individual dose received by occupational workers along with dose limit (ICRP, 2007, IAEA GSR part-3, 2014).

\section{Individual and collective dose distribution ratio}

The individual dose distribution ratios in the 5-year periods were presented in Table III. It is seen that very few individuals were exposed to doses exceeding 10 and $15 \mathrm{mSv}$. Furthermore, $<4 \%$ of the monitored workers received doses above $10 \mathrm{mSv}$. Table IV presents the results of the collective dose distribution ratio in the 5-year periods. 
Table III: The individual dose distribution ratio for 2010-2014 periods.

\begin{tabular}{|l|c|c|c|c|c|}
\hline \multirow{2}{*}{$\begin{array}{l}\text { Annual individual dose } \\
\text { exceeding (mSv) }\end{array}$} & \multicolumn{5}{|c|}{ Individual dose distribution ratio } \\
\cline { 2 - 6 } & 2010 & 2011 & 2012 & 2013 & 2014 \\
\hline 15 & 0.00 & 0.021 & 0.021 & 0.022 & 0.009 \\
\hline 10 & 0.009 & 0.021 & 0.042 & 0.022 & 0.009 \\
\hline 5 & 0.048 & 0.117 & 0.179 & 0.100 & 0.078 \\
\hline 1 & 0.298 & 0.276 & 0.411 & 0.267 & 0.284 \\
\hline
\end{tabular}

Table IV: Collective dose distribution ratio for 2010-2014 periods.

\begin{tabular}{|l|c|c|c|c|c|}
\hline \multirow{2}{*}{$\begin{array}{l}\text { Annual individual dose } \\
\text { exceeding }(\mathrm{mSv})\end{array}$} & \multicolumn{5}{|c|}{ Collective dose distribution ratio } \\
\cline { 2 - 6 } & 2010 & 2011 & 2012 & 2013 & 2014 \\
\hline 15 & 0.00 & 0.371 & 0.278 & 0.473 & 0.112 \\
\hline 10 & 0.194 & 0.371 & 0.375 & 0.473 & 0.112 \\
\hline 5 & 0.332 & 0.712 & 0.687 & 0.706 & 0.376 \\
\hline 1 & 0.722 & 0.886 & 0.861 & 0.833 & 0.534 \\
\hline
\end{tabular}

\section{ConcLusion}

Occupational exposure to ionization radiation in interventional cardiology practices in Bangladesh and dose trends for the years 2010-2014 are presented. For the 5-year periods, no occupational workers were found to have received an effective dose $>50 \mathrm{mSv}$ in a single year or $>100 \mathrm{mSv}$ in a consecutive 5-year periods. Therefore, occupational exposures to ionizing radiation of all workers in interventional cardiology practices are lower than the prescribed dose limit recommended by International Organizations. However, very few workers individual effective doses are higher than recommended average annual dose limit $\left(20 \mathrm{mSv} \cdot \mathrm{y}^{-1}\right)$. Therefore, occupational workers in interventional cardiology practices should pay more attention to radiation protection procedures and guidelines to keep the doses below the annual average dose limit other than the maximum allowable dose limit in a year. The status and trends in occupational exposure demonstrate that radiation protection conditions at the majority of the workplace were adequate. Despite that, further optimization is necessary due to large variations observed in the maximum individual doses over the 5-year periods.

\section{ACKNOWLEDGEMENT}

The authors wish to express their gratitude to their colleagues for their support. The International Atomic Energy Agency (IAEA) is thanked for providing TLD readers whose data were reported in this study.

\section{REFERENCES}

Basic, B., Beganovic, A., Samek, D., Skopljak-Beganovic, A. and Gazdic -Santic, M. (2010), "Ten years of monitoring the occupational radiation exposure in Bosnia and Herzegovina", Radiat. Prot. Dosim., Vol. 139 (1-3), pp 400-402.

Beganovic, A., Kulic, M., Spuzic, M., Gazdic-Santic, M., Skopljak-Beganovic, A., Drljevic, A., Dzanic, S., Basic, B. and Lincender, L. (2010), "Patient doses in interventional cardiology in Bosnia and Herzegovina: first result", Radiat. Prot. Dosim., Vol. 139 (1-3), pp $254-257$.

Ciraj-Bjelac, O., Rehani, M.M., Sim, K.H., Liew, H.B., Vano, E. and Kleiman, N.J.(2010), “Risk for radiation-induced cataract for staff in interventional cardiology: is there reason for concern?", Catheter. Cardiovasc. Interv., Vol. 76(6), pp 826-834.

Harshaw TLD Model 6600 Plus Automatic TLD reader user manual (2007). Thermo Fisher Scientific Inc., Available on http://www.kortec.cz/files/thermo/TLDModel6600.pdf.

International Atomic Energy Agency (1999). Assessment of occupational exposures due to external sources of radiation. Safety Guides Series No. RS-G-1.3.

International Atomic Energy Agency (2014). Radiation Protection and Safety of Radiation Sources: International Basic Safety Standards. General Safety Requirements Part-3.

International Commission on Radiological Protection (1997). General Principles for the radiation protection of workers, First ed. Annals of the ICRP 27 (1) Pergamon.

International Commission on Radiological Protection (ICRP) (2007). The 2007 Recommendations of International Commission on Radiological Protection. ICRP Publication 103. Ann. Of ICRP 37 (2- 4) Elsevier.

Jacob, S., Michel, M., Spaulding, C., Boveda, S., Bar, O., Brezin, A.P., Streho, M., Maccia, C., Scanff, P., Laurier, D. and Bernier, M. (2010), "Occupational cataracts and lens opacities in interventional cardiology (O'CLOC study): are X-rays involved?", BMC Public Health, Vol. 10, pp 537.

United Nations Scientific Committee on the Effects of Atomic Radiation (2000). Report to the General Assembly. United Nations, New York, USA. 
Vano, E., Gonzalez, L., Beneytez, F. and Moreno, F.(1998), "Lens injuries induced by occupational exposure in non-optimized interventional radiology laboratories", Br. J Radiol., Vol. 71, pp 728-733.

Vano, E., Gonzalez, L., Guibelalde, E., Fernandez, J.M. and Ten, J.I. (1998), “Radiation exposure to medical staff in interventional and cardiac radiology", Br. J Radiol., Vol. 71, pp 954-960.

\section{--0 --}

